\title{
Reproductive isolation between two species of flour beetles, Tribolium castaneum and T. freemani: variation within and among geographical populations of $T$. castaneum
}

\author{
MICHAEL J. WADE* \& NORMAN A. JOHNSON \\ Department of Ecology and Evolution, 1101 E. 57th Street, University of Chicago, Chicago, IL 60637, USA
}

\begin{abstract}
Tribolium castaneum and T. freemani produce sterile hybrid progeny in reciprocal crosses. The reciprocal crosses differ significantly in the mean numbers of progeny, progeny sex ratios, hybrid male body size and male antennal and leg morphologies. These results suggest an effect of either the $\mathrm{X}$ chromosome or the cytoplasm on characteristics of $F_{1}$ hybrids. In contrast, large $\mathrm{X}$ chromosome effects on morphological traits are not usually oberved in interspecific crosses among drosophilid flies. We also report large, significant differences in progeny numbers, body mass and degree of female bias in sex ratio between different geographic strains of $T$. castaneum when mated in reciprocal crosses with $T$. freemani. Sex ratio bias also varies significantly among matings within geographic strains of $T$. castaneum. When $T$. castaneum males are mated with $T$. freemani females, but not in the reciprocal cross, the $F_{1}$ sex ratio is female biased, uncorrelated with family size and ranges from 57.14 per cent to 72.23 per cent female, depending on the geographic strain of the $T$. castaneum male.
\end{abstract}

Keywords: hybrid inviability, genetic variation, morphology, reproductive isolation, speciation, Tribolium

\section{Introduction}

Dobzhansky (1937), Mayr (1963) and others (Coyne et al., 1988; Coyne, 1992b; Wu \& Davis, 1993) have argued that the evolution of genetic reproductive isolation is critical to the formation of new species. One type of reproductive isolation is hybrid inviability. Although there is a burgeoning volume of information about the patterns and the genetics of hybrid inviability in drosophilid flies (Crow, 1942; Watanabe, 1979; Bock, 1984; Coyne \& Orr, 1989a,b; Hutter et al., 1990; Sawamura et al., 1993a,b); Orr, 1993; Wu \& Davis, 1993), little is known about the genetic basis of hybrid inviability in other taxa, such as the notably speciose Coleoptera.

Coyne \& Orr (1989a) have directed attention to two empirical generalizations about the genetics of postmating reproductive isolation. The first of these is Haldane's rule (Haldane, 1922) which states that in crosses between different animal races or species, if there is sterility or inviability in one but not the other sex of the $F_{1}$ hybrids, it is most often the heterogametic

*Correspondence. sex that is most adversely affected. This rule applies to taxa in which males are the heterogametic sex (including beetles) as well as in cases wherein females are the heterogametic sex. Recently a number of authors (Wu, 1992; Wu \& Davis, 1993; Orr, 1993; Partridge, 1993) have come to the conclusion that Haldane's rule is probably a composite phenomenon with different explanations applicable to different aspects (sterility vs. inviability, heterogametic males vs. heterogametic females) of the rule. Although no complete inviability of either sex has been observed in the hybrids of crosses between $T$. castaneum and $T$. freemani (Brownlee \& Sokoloff, 1988), it is not known whether there are more subtle differences in the viabilities of the two sexes in the hybrids.

The second empirical generalization is the large effect of the $\mathrm{X}$ chromosome. In most cases of postmating reproductive isolation (most strongly supported for cases of hybrid sterility), the $\mathrm{X}$ chromosome has a disproportionate effect. This rule does not seem to apply to traits involved in premating (behavioural) reproductive isolation (Coyne, 1989, 1992a, 1993) or to morphological traits (Coyne, 1985; Charlesworth et al., 1987; Coyne \& Orr, 1989a; Spicer, 1991; but see 
Templeton, 1977). These generalizations, however, have been based almost exclusively on data from Drosophila genetic studies. We can infer whether a large $\mathrm{X}$ effect exists from a comparison of the male morphologies of the $F_{1}$ from reciprocal crosses (which differ only in the source of the $\mathrm{X}$ chromosome, $\mathrm{Y}$ chromosome and cytoplasm).

Tribolium castaneum is a human commensal species of flour beetle with a worldwide distribution found in a variety of stored products (Sokoloff, 1974). T. freemani is two to three times the mass of $T$. castaneum but otherwise morphologically and karyotypically similar (eight pairs of autosomes, females XX, males XY) (Hinton, 1948; Sokoloff, 1974; Nakakita et al., 1981; Brownlee \& Sokoloff, 1988). Certain geographic and laboratory genetic strains of $T$. castaneum produce large numbers of $F_{1}$ progeny in reciprocal hybridizations with $T$. freemani. In many cases, the productivity of $F_{1}$ crosses is comparable to that found in intraspecific crosses (see below). Nearly all the hybrids of both sexes are sterile or, at best, a few (less than 1.33 per cent) are very weakly fertile (producing fewer than five progeny) (Brownlee \& Sokoloff, 1988; Wade et al., 1994; see below).

These two species do not exhibit any detectable premating reproductive isolation (Wade et al., 1993), consistent with the indiscriminate nature of mating within Tribolium (Park, 1933; Sokoloff, 1974). Some kind of postcopulatory but prezygotic reproductive isolation exists between these two species (Wade et al., 1994): when females of either species mate with both conspecific and heterospecific males, almost all offspring are sired by the conspecific male (i.e. few hybrids are produced) (Wade et al., 1994).

Here, we report variation in the numbers of $F_{1}$ progeny, progeny sex ratio and $F_{1}$ body size within and between geographical strains of $T$. castaneum when reciprocally hybridized with $T$. freemani. The empirical literature on the genetic basis of reproductive isolation often ignores variation in the degree of reproductive isolation between interbreeding species that may exist within or among populations of either species. Consequently, there are few studies of intraspecific variation in features of interspecific hybridization. Those that do exist generally focus on variation in major genes, such as $h m r$ (hybrid male rescue) which rescues inviable $F_{1}$ male progeny in crosses between Drosophila melanogaster and $D$. simulans (see Watanabe, 1979; Hutter et al., 1990; Sawamura et al., 1993a,b). In contrast, most scenarios for the evolution of genetic reproductive isolation between species implicitly assume heterogeneity within populations. They postulate the adventitious fixation within each of two species of genes affecting reproductive isolation occurring as an incidental by- product of the forces of natural selection and/or random genetic drift (Dobzhansky, 1937; Mayr, 1963; Carson, 1975; Templeton, 1980; Nei et al., 1983; Charlesworth et al., 1987). In highly subdivided populations, local adaptations that might affect the degree of reproductive isolation with another species will spread slowly through the species by migration if globally adaptive but the extent of their spread could be quite restricted if only locally adaptive. In addition, if random genetic drift were responsible for the reproductive isolation between species (see Nei et al., 1983), we would also expect considerable heterogeneity among populations from limited migration within species early in the speciation process. Thus, in the early stages of speciation there might be considerable intraspecific genetic variation for pre- and postmating reproductive isolation, not only between reciprocal crosses among species but also, or even especially, among populations within a species.

In this study of the species pair, T. castaneum and $T$. freemani, we report finding such intraspecific variation in hybrid progeny numbers, the degree of female sex ratio bias and male body size at three levels: (1) variation between reciprocal crosses, (2) variation among different geographic and laboratory strains of $T$. castaneum, and (3) variation among individuals or families within strains.

\section{Materials and methods}

Virgin male and female $T$. freemani were mated individually to virgins from one of several strains of $T$. castaneum. The following five strains of $T$. castaneum were used: (A) c-SM: an outbred mixture of the four classic 'Park' strains (Park et al., 1964; Wade, 1977), (B) c-pl: a strain segregating the pearl eye mutation obtained from Dr R. Beeman at the USDA Grain Research Marketing Laboratory at Lawrence, Kansas, (C) c-Yugo: a wild strain collected in 1979 in the former Yugoslavia, now Croatia, (D) c-BS: a wild strain collected in 1987 in Naperville, Illinois, and (E) c-Inf: a wild strain collected in 1979 in Infantes, Spain. The c-SM strain is an outbred laboratory strain and the last three wild strains were derived from collections consisting of at least 50 adults each. The $T$. freemani strain used was the standard stock, collected in 1978 (Nakakita et al., 1981) from a shipment of grain to Japan from Chile.

For each of the above strains, except c-BS and c-Inf, 25-28 replicates of reciprocal crosses were established in an 8 dram vial containing $8 \mathrm{~g}$ of standard medium (95 per cent sifted stoneground flour, 5 per cent yeast; see Wade, 1977). For c-BS, 15-17 reciprocal crosses were set up but for c-Inf only nine matings of males to 
T. freemani females were set up. All pairs were maintained in a darkened incubator at $29^{\circ} \mathrm{C}$ with 70 per cent relative humidity for 55 days. We note that as each family was raised in just one vial, the among-family effects described in Results below may occur from vial effects rather than from genetic differences. (In related work, repeated observations on single females of both species indicate significant family as opposed to vial effects (R. Jones and M. J. Wade, unpublished data).)

After 55 days, all cultures were sifted and the offspring were censused, separated by sex and weighed to the nearest $0.01 \mathrm{mg}$ on a Mettler AE163 balance. At this time, morphological abnormalities of the antennae and legs of individual beetles were also noted. Statistical tests were performed using the STATISTICA STATSOFT computer software package.

We will discuss the results of the interspecific crosses first by geographic strain of $T$. castaneum and then review patterns common to all geographic strains. The two laboratory strains, the outbred c-SM and the mutant stock, c-pl, will be discussed first, followed by data for the three wild stocks, c-Yugo (Zagreb), c-BS (Naperville, IL) and c-Inf (Infantes, Spain).

\section{Results}

We first describe the major features of productivity and sex ratio of the reciprocal crosses of each strain of $T$. castaneum when hybridized to $T$. freemani .

\section{c-SM hybridizations with $\mathrm{T}$. freemani}

Crosses between $T$. castaneum males and $T$. freemani females $(\mathrm{c}-\mathrm{SM} \times \mathrm{F})$ are less likely to fail to produce progeny $(3$ of 25 vs. 9 of 25 in reciprocal matings, $\left.\chi^{2}=3.95,0.025<P<0.050\right)$ and produce significantly more progeny than the reciprocal cross, $\mathrm{F} \times \mathrm{c}-\mathrm{SM}$ (Table 1). The sex ratio of the $\mathrm{c}-\mathrm{SM} \times \mathrm{F}$ progenies (62.75 per cent female) differed significantly from unity ( $G$-test, 1 d.f., $G=42.547, P<0.001$ ). The progenies of different families also varied significantly in sex ratio from one another ( $G$-heterogeneity $=$ 51.60, 21 d.f., $P<0.001)$, ranging from 87 per cent females ( 33 females of 38 ) to 36 per cent females (9 females of 25). We observed no correlation between family size at day 55 and sex ratio $(r=-0.043,17$ d.f. $)$. We noted that many male, but not female, hybrids in this cross were missing several of the terminal antennal segments or the entire antennae, which appeared to be broken off. Complete data were gathered from four families in which 15 of 39 males or 38 per cent exhibited this condition but none of 86 females did so. (See c-BS hybridization with T. freemani for a complete study of all families in the c-BS strain.)
The reciprocal cross, $\mathrm{F} \times \mathrm{c}-\mathrm{SM}$, experienced more failed matings ( 9 of 25) and nearly 60 per cent lower productivity per cross (Table 1 ). The progeny sex ratio, 52.02 per cent females, was not significantly different from unity $(G=0.607,1$ d.f.) although it did differ from that of the reciprocal cross $\left(\chi^{2}=11.029,1\right.$ d.f., $P<0.001)$. The $\mathrm{F} \times \mathrm{c}-\mathrm{SM}$ families were not significantly heterogeneous in sex ratio ( $G$-heterogeneity $=21.003,16$ d.f.). Only 6 male and 6 females of 371 total (3.2 per cent) exhibited the friability of antennal segments commonly observed in males of the reciprocal cross (see above).

Of $300 \mathrm{c}-\mathrm{SM} \times \mathrm{F}$ female hybrids tested, only 3 females were weakly fertile, each producing fewer than 3 larvae in backcrosses to either T. castaneum or $T$. freemani males. None of the 120 reciprocal hybrid females tested was fertile. Overall, 0.71 per cent $(3$ of 420) of all hybrid females were weakly fertile.

Hybrid males of the cross F male $\times$ c-SM female had a mean weight of $2.944 \mathrm{mg}$ with a standard error of $0.03832 \mathrm{mg}(N=148)$. This was much closer to the mean of the weights of pure species c-SM /mean weight of c-SM males $2.370 \mathrm{mg}$, standard error $=0.04532 \mathrm{mg}$, $N=23$; mean of weight of c-SM females $2.493 \mathrm{mg}$, standard error $=0.03392 \mathrm{mg}, N=24)$ than it was to the mean of pure species $T$. freemani (male mean $=6.013$ $\mathrm{mg}$, standard error $=0.1181 \mathrm{mg}, \quad N=22$; female mean $=6.106 \mathrm{mg}$, standard error $=0.1645 \mathrm{mg}$, $N=16$ ). There was significant among-family variation for male weight in this cross (ANOVA, 14 among d.f., 133 error d.f., $F=16.387, P \ll 0.0001$ ). Hybrid females of this cross were heavier, averaging $3.707 \mathrm{mg}$ with a standard error of $0.04208 \mathrm{mg}(N=173)$. There was also significant heterogeneity among families for hybrid female weight (ANOVA, 14 among d.f., 158 error d.f., $F=6.771, P \ll 0.0001)$. The male and female mean weights across families were highly correlated (Spearman's rank order correlation, $r=0.878, P<0.0001)$.

In the reciprocal cross (c-SM male $\times \mathrm{F}$ female), the hybrid females weighed on average $4.412 \mathrm{mg}$ with a standard error of $0.03246 \mathrm{mg}(N=182)$. There was significant heterogeneity among families for female weight in this cross (ANOVA, 18 among d.f., 163 error d.f., $F=2.351, P=0.0250)$. From this cross, there were too few males (19) which survived at the time of weighing to warrant inclusion in these data.

\section{$c-p /$ hybridizations with $\mathrm{T}$. freemani}

Crosses between c-pl males and T. freemani females (c$\mathrm{pl} \times \mathrm{F}$ ) fail to produce progeny more often than the reciprocal cross, $\mathrm{F} \times \mathrm{c}-\mathrm{pl}$ ( 4 of 25 vs. 0 of 25 matings, chi-square $4.34,0.025<P<0.050)$ and they produce strikingly fewer progeny (Table 1 ). The sex ratio of the 
Table 1 Mean and standard error of the numbers of male and female progeny produced in crosses between T. castaneum and T. freemani

\begin{tabular}{|c|c|c|c|c|}
\hline \multirow[b]{2}{*}{$\begin{array}{l}\text { Strain of } \\
\text { T. castaneum }\end{array}$} & \multicolumn{2}{|c|}{ C-male $\times$ F-female } & \multicolumn{2}{|c|}{ F-male $\times C$-female } \\
\hline & $\begin{array}{l}\text { Male } \\
\text { Mean (S.E.) }\end{array}$ & $\begin{array}{l}\text { Female } \\
\text { Mean (S.E.) }\end{array}$ & $\begin{array}{l}\text { Male } \\
\text { Mean (S.E.) }\end{array}$ & $\begin{array}{l}\text { Female } \\
\text { Mean (S.E.) }\end{array}$ \\
\hline $\begin{array}{l}\text { c-SM } \\
\text { Total }\end{array}$ & \multicolumn{2}{|c|}{$25.9(3.24)$} & \multicolumn{2}{|c|}{$14.8(3.18)$} \\
\hline $\begin{array}{l}\text { c-pl } \\
\text { Total }\end{array}$ & \multicolumn{2}{|c|}{$28.5(3.38)$} & \multicolumn{2}{|c|}{$80.4(6.89)$} \\
\hline $\begin{array}{l}\text { c-Yugo } \\
\text { Total }\end{array}$ & \multicolumn{2}{|c|}{$30.3(2.06)$} & \multicolumn{2}{|c|}{$66.6(6.89)$} \\
\hline $\begin{array}{l}\text { c-BS } \\
\text { Total }\end{array}$ & \multicolumn{2}{|c|}{$17.9(3.47)$} & \multicolumn{2}{|c|}{$29.5(6.53)$} \\
\hline $\begin{array}{l}\text { c-Inf } \\
\text { Total }\end{array}$ & \multicolumn{2}{|c|}{$27.0(4.04)$} & \multicolumn{2}{|c|}{-} \\
\hline
\end{tabular}

c-pl $\times \mathrm{F}$ progenies averaged 72.23 per cent female, the largest average difference of any strain from a sex ratio of unity ( $G$-test, 1 d.f., $G=145.993, P \ll 0.001)$. These progenies were also extremely heterogeneous in sex ratio $(G$-heterogeneity $=93.45,20$ d.f., $P \ll 0.001)$, ranging from 97 per cent females ( 32 females of 33 ) to 47 per cent females ( 25 females of 47 ). There was no significant correlation between family size at day 55 and sex ratio $(r=+0.275,19$ d.f.). Lastly, we noted that many of the male hybrids in this cross, but never females, had several of the distal antennal segments and the tarsi broken off.

The reciprocal cross, $\mathrm{F} \times \mathrm{c}$-pl, experienced no failed matings at all ( 0 of 25$)$ and nearly a threefold higher productivity per cross (Table 1 ). The average progeny sex ratio was slightly but significantly female biased, 53.16 per cent females $(G=7.969,1$ d.f., $P<0.005)$. Although female biased, it was much less skewed towards females than the sex ratio of the reciprocal hybrids $\left(\chi^{2}=78.636,1\right.$ d.f., $\left.P \ll 0.001\right)$. The $\mathrm{F} \times \mathrm{c}$-pl families were also significantly heterogeneous in sex ratio $(G$-heterogeneity $=51.886,24$ d.f., $P<0.001$ ), ranging from 70.3 per cent females ( 71 of 101) to 37.9 per cent females ( 25 of 66 ). Neither males nor females of this cross were found to have broken antennae or tarsi despite the much higher densities.

None of the $180 \mathrm{~F} \times \mathrm{c}-\mathrm{pl}$ or $90 \mathrm{c}-\mathrm{pl} \times \mathrm{F}$ female hybrids tested was fertile in backcrosses to either $T$. castaneum or $T$. freemani males.

Hybrid males from the $\mathrm{F} \times \mathrm{c}$-pl cross had a mean weight of $2.900 \mathrm{mg}$ with a standard error of 0.01783 $\mathrm{mg}(N=322)$. There was significant among-family variation in the weights of these males (ANOVA, 5 among d.f., 316 error d.f., $F=14.974, P \ll 0.0001)$. Hybrid females resulting from this cross weighed on average $3.857 \mathrm{mg}$ with a standard error of $0.02084 \mathrm{mg}$ $(N=280)$. The weights of these females also were significantly heterogeneous among families (ANOVA, 4 among d.f., 275 error d.f., $F=11.632, P \ll 0.001)$. There were not enough families, for which we obtained data on both male and female weights, to test for a correlation. No measurements were made on the offspring from the reciprocal cross.

\section{c-Yugo hybridizations with $\mathrm{T}$. freemani}

Crosses between $T$. castaneum males from Yugoslavia and $T$. freemani females $(\mathrm{c}-Y$ ugo $\times \mathrm{F})$ are as likely as the reciprocal cross to fail to produce progeny ( 0 of $28 \mathrm{vs}$. 2 of 28 , respectively) but they produce far fewer progeny per female (Table 1). The sex ratio of the c-Yugo $\times \mathrm{F}$ progenies was 57.14 per cent female, significantly different from unity $(G$-test, 1 d.f., $G=17.19$, $P<0.001)$. There was conspicuous heterogeneity in progeny sex ratio among families $(G$ heterogeneity $=73.42,27$ d.f., $P<0.001)$, ranging from 100 per cent females ( 27 females of 27 ) to 45 per cent females ( 19 females of 42 ). We observed no correlation between family size at day 55 and sex ratio $\langle r=-0.040,26$ d.f. $\rangle$. We did not note any male morphological abnormalities in this strain.

The reciprocal cross, $\mathrm{F} \times \mathrm{c}$-Yugo, was more than twice as productive (Table 1). The progeny sex ratio, 51.59 per cent females, here did not differ from unity $(G=1.62,1$ d.f.) but did differ significantly from its reciprocal $\left(\chi^{2}=6.875,1\right.$ d.f., $\left.P<0.01\right)$. The 
$\mathrm{F} \times \mathrm{c}$-Yugo families were also significantly heterogeneous in sex ratio ( $G$-heterogeneity $=42.98,25$ d.f.), ranging from 66.3 per cent females ( 69 of 104) to 31.0 per cent females ( 13 of 42 ).

The $150 \mathrm{c}$-Yugo $\times \mathrm{F}$ hybrid females were tested by backcrossing to males of the parental species. In two cases, hybrid females backcrossed to $T$. castaneum males were weakly fertile, each producing fewer than five larvae. In backscrosses of $150 \mathrm{~F} \times \mathrm{c}$-Yugo female hybrids, two females were weakly fertile when mated with $T$. freemani males.

The F $\times$ c-Yugo hybrid males had a mean weight of $2.996 \mathrm{mg}$ with a standard error of $0.03772 \mathrm{mg}$ $(N=152)$ whereas their sisters had a mean weight of $3.844 \mathrm{mg}$ with a standard error of $0.03143 \mathrm{mg}$ $(N=296)$. In the reciprocal cross $(c-Y u g o \times F)$, hybrid males had a mean weight of $4.7452 \mathrm{mg}$ and a standard error of $0.04975 \mathrm{mg}(N=143)$. The females of this cross had a mean weight of $3.876 \mathrm{mg}$ with a standard error of $0.02225 \mathrm{mg}(N=316)$. These hybrids were not grouped by family so we could not test for a family effect.

\section{$c-B S$ hybridizations with $\mathrm{T}$. freemani}

Crosses between $T$. castaneum-BS males and $T$. freemani females $(\mathrm{c}-\mathrm{BS} \times \mathrm{F})$ are less likely to fail to produce progeny ( 1 of 15 matings vs. 5 of 17 matings; chi-square 2.706 , not significant) but produce significantly fewer progeny than the reciprocal cross, $\mathrm{F} \times \mathrm{c}$ BS (Table 1). The sex ratio of the $\mathrm{c}-\mathrm{BS} \times \mathrm{F}$ progenies ( 59.85 per cent female) differed significantly from unity ( $G$-test, 1 d.f., $G=48.22, P<0.001$ ). The progenies also varied significantly in sex ratio from one another ( $G$-heterogeneity $=37.61,14$ d.f., $P<0.001)$, ranging from 85 per cent females ( 23 females of 28 ) to 42 per cent females ( 11 females of 26 ). We observed no correlation between family size at day 55 and sex ratio $(r=-0.180,9$ d.f. (omitting three families with fewer than seven progeny)). We observed missing or broken antennal segments in 31 of 108 males ( 29 per cent) but only in a single female (1 of 161).

The reciprocal cross, $\mathrm{F} \times \mathrm{c}-\mathrm{BS}$, had a greater proportion of failed matings ( 5 of 17) and 64 per cent greater productivity per cross (Table 1 ). The progeny sex ratio (49.50 per cent females) was not significantly different from unity but did differ from that of the reciprocal cross $\left(\chi^{2}=7.52,1\right.$ d.f., $\left.P<0.010\right)$. The $\mathrm{F} \times \mathrm{c}$-BS families were not significantly heterogeneous in sex ratio ( $G$-heterogeneity $=8.539,15$ d.f.). Only a single male out of a total of 253 was missing any of its antennal segments and none of 248 females had damaged antennal segments.
Of the 200 female hybrids tested for fertility by backcrossing to the parental species, only $1 \mathrm{~F} \times \mathrm{c}-\mathrm{BS}$ female produced a single offspring when crossed to a $T$. castaneum c-SM male. None of the 770 mass mated hybrids produced progeny, suggesting that the males are also sterile.

$\mathrm{F} \times \mathrm{c}-\mathrm{BS}$ hybrid females had a mean weight of 3.452 $\mathrm{mg}$ with a standard error of $0.02173 \mathrm{mg}(N=239)$. There was significant variation in weight among ten randomly selected families (ANOVA, 9 among d.f., 229 error d.f., $F=7.521, P \ll 0.0001)$. Hybrid males of this same cross weighed on average $2.608 \mathrm{mg}$ with a standard error of $0.01908 \mathrm{mg}(N=249)$ but no significant variation among eight different families was found (ANOVA, 7 among d.f., 241 error d.f., $F=1.352$, $P>0.05)$.

In the reciprocal cross $(\mathrm{c}-\mathrm{BS} \times \mathrm{F})$, hybrid females averaged $3.850 \mathrm{mg}$ in weight with a standard error of $0.03352 \mathrm{mg}(N=101)$. There was also significant among-family variation in the female weights (ANOVA, 4 among d.f., 96 error d.f., $F=7.581$, $P \ll 0.0001)$. The hybrid males of this cross weighed $4.331 \mathrm{mg}$ with a standard error of $0.06777 \mathrm{mg}$ $(N=105)$. These males were not grouped by family.

\section{c-Inf hybridizations with $\mathrm{T}$. freemani}

Only nine crosses of c-Inf males to $T$. freemani females were set up and one of these failed to produce any progeny. The average progeny sex ratio was 70.4 per cent female $(G=20.566,1$ d.f., $P \ll 0.001)$ and the hybrid families varied from one another in sex ratio $(G$ heterogeneity $=23.62,7$ d.f., $P<0.005)$, ranging from 91.9 per cent female ( 37 of 40 ) to 47.1 per cent female (16 of 34).

Of the 120 hybrid females testcrossed to pure species males, one proved to be weakly fertile when crossed with a $T$. freemani male.

\section{Summary of crosses and comparisons among $\mathrm{T}$. castaneum strains}

In Table 2, we summarize the sex ratio data for the different strains of $T$. castaneum hybridized to $T$. freemani. In all crosses to $T$. freemani females, progenies exhibited significantly female biased sex ratios and significant heterogeneity among families within strains in sex ratio. The strains of $T$. castaneum also differ significantly from one another in the degree of female bias $(G-$ heterogeneity $=45.504,4$ d.f., $P \ll 0.001$ ). There is no obvious tendency for the degree of female bias to be negatively correlated with average family size at day 55 as the strain with the least bias, c-Yugo, has the largest average family size. 
Table 2 Sex ratio of $F_{1}$ hybrids between different strains of T. castaneum and T. freemani

\begin{tabular}{|c|c|c|}
\hline $\begin{array}{l}\text { Strain of } \\
\text { T. castaneum }\end{array}$ & $\begin{array}{l}\mathrm{C} \text {-male } \times \text { F-female } \\
\text { Female }(\mathrm{N}) \\
(\%)\end{array}$ & $\begin{array}{l}\text { F-male } \times \text { C-female } \\
\text { Female }(\mathrm{N}) \\
(\%)\end{array}$ \\
\hline$c-S M$ & $62.75(647) \dagger$ & $52.02(371)$ \\
\hline c-pl & $72.23(713) \dagger$ & $53.16(2009) \dagger$ \\
\hline c-Yugo & $57.14(847) \dagger$ & $51.59(1605) \ddagger$ \\
\hline $\mathrm{c}-\mathrm{BS}$ & $59.85(269) \dagger$ & $49.50(501)$ \\
\hline c-Inf & $70.40(243) \dagger$ & - \\
\hline
\end{tabular}

$\dagger$ Indicates significant female bias and significant heterogeneity in sex ratio among families.

FIndicates significant heterogeneity among families in sex ratio.

In the reciprocal cross to T. freemani males, only the laboratory mutant strain, c-pl, exhibited a small but significant female bias in hybrid sex ratio. It was not as female-biased as any of the reciprocal crosses to $T$. freemani females. The sex ratios were not heterogeneous among strains, however $(G$-heterogeneity $=2.440$, 3 d.f., not significant). Both the c-Yugo and c-pl strains exhibited very significant among-family variation in sex ratio. However, in both strains, the most heavily female-biased families exhibited sex ratios below the average sex ratio observed in most of the reciprocal crosses.

The relative size of male and female $F_{1}$ hybrids differed between the reciprocal crosses (summarized in Table 3). Hybrid males were generally 15 per cent larger than hybrid females when $T$. freemani was the mother but males were 25 per cent smaller than females when $T$. castaneum was the mother. Hybrid male weight in the former cross was 1.65 times as great as in the latter. Females of both pure species weigh up to 10 per cent more than males as is typical of species in the genus (see above; Sokoloff, 1974). The sex difference in weight in the hybrids is greater than that observed within the parent species and, in one of the interspecific crosses, the sexual dimorphism in size is reversed.

In three strains, c-SM, c-pl and c-BS, we noted the integrity of antennal segments in males and females of both reciprocal crosses. When crossed to $T$. freemani females, male but not female hybrids exhibited fragile or friable antennal segments. In both c-SM and c-BS, the incidence is approximately $30-40$ per cent of all hybrid males. This condition was not observed to any significant degree in either sex in the reciprocal crosses of females of these strains to T. freemani males.
Table 3 Summary of weights of hybrid males and temales

\begin{tabular}{|c|c|c|c|c|}
\hline & \multicolumn{4}{|c|}{ T. castaneum strain } \\
\hline & $\mathrm{c}-\mathrm{SM}$ & c-pl & c-Yugo & $\mathrm{c}-\mathrm{BS}$ \\
\hline \multicolumn{5}{|l|}{$F \times c \dagger$} \\
\hline Males & $\begin{array}{l}2.944 \dagger \\
0.03832 \\
(148)\end{array}$ & $\begin{array}{l}2.900 \\
0.01783 \\
(322)\end{array}$ & $\begin{array}{l}2.996 \\
0.03772 \\
(152)\end{array}$ & $\begin{array}{l}2.608 \\
0.01908 \\
(249)\end{array}$ \\
\hline Females & $\begin{array}{l}3.707 \\
0.04208 \\
(173)\end{array}$ & $\begin{array}{l}3.852 \\
0.02084 \\
(280)\end{array}$ & $\begin{array}{l}3.844 \\
0.03143 \\
(296)\end{array}$ & $\begin{array}{l}3.452 \\
0.02173 \\
(239)\end{array}$ \\
\hline \multicolumn{5}{|l|}{$c \times F$} \\
\hline Males & - & - & $\begin{array}{l}4.742 \\
0.04975 \\
(143)\end{array}$ & $\begin{array}{l}4.331 \\
0.06777 \\
(105)\end{array}$ \\
\hline Females & $\begin{array}{l}4.412 \\
0.03246 \\
(182)\end{array}$ & - & $\begin{array}{l}3.876 \\
0.02225 \\
(316)\end{array}$ & $\begin{array}{l}3.850 \\
0.03352 \\
(101)\end{array}$ \\
\hline F-c males $\S$ & - & - & 1.746 & 1.723 \\
\hline F-c females $\S$ & 0.705 & - & 0.032 & 0.398 \\
\hline
\end{tabular}

$\dagger \mathrm{F} \times \mathrm{c}$ represents the cross of a $T$. freemani male to a $T$. castaneum female; $\mathrm{c} \times \mathrm{F}$ is the reciprocal cross.

$\neq$ Upper number is the mean weight in $\mathrm{mg}$, middle number is the S.E.M. The number tested is in parentheses.

$\S \mathrm{F}-\mathrm{c}$ males and F-c females represents the difference in the weights in hybrid males and females, respectively, from the cross in which $T$ - freemani is the female and the cross in which T. castaneum is the female.

\section{Discussion}

Our observations are consistent with the inviability aspect of Haldane's rule in that when one sex in the $F_{1}$ is rarer it is the males (which are heterogametic in Tribolium). For each of the five strains of T. castaneum males mated to T. freemani females and in two of four reciprocal crosses, we observed significant heterogeneity among families in progeny sex ratios. In some cases, the variation ranged from a complete absence of males to equality of sex ratio. However, no correlation within any geographical or laboratory strain was seen between family size at day 55 and the degree of sex ratio bias in favour of females. A negative correlation between family size and degree of female bias might be expected if male mortality were responsible for the rarity of males. With the number of crosses observed, we should have been able to detect a correlation of 0.45 at the 0.05 level; the observed correlations were all smaller (see above). Of course, mortality observa- 
tions comparing the numbers of adults at day 55 to the numbers of eggs laid or larvae hatched would be more conclusive. (Preliminary observations on work in progress suggest that the rarity of males is due to mortality.)

We have observed that morphological abnormalities (for instance, broken distal antennal segments and deformities of the distal leg segments) occur more often in hybrids of the heterogametic sex (male) than in the homogametic sex. Thus we have observed a morphological equivalent of Haldane's rule.

Data from Drosophila hybridizations also strongly suggest that hybrid male sterility evolves much faster than hybrid female sterility or hybrid inviability (Coyne \& Orr, 1989b; Wu, 1992; Wu \& Davis, 1993; Johnson $\& \mathrm{Wu}, 1993)$. Our data are consistent with a faster rate of evolution to hybrid sterility compared with that to hybrid inviability as most hybrids of both sexes are sterile and none approaches normal fertility. In contrast, the hybrids from most of the crosses appear to have intermediate to normal viability.

The large difference in weights between reciprocal $F_{1}$ males suggests that the $\mathrm{X}$ chromosome, the $\mathrm{Y}$ chromosome and/or the cytoplasm have a disproportionate effect on this morphological trait. Because the reciprocal $F_{1}$ females, who also have different sources of their cytoplasm, do not demonstrate as large a difference in weights, it is more probable that the $\mathrm{X}$ or the $\mathrm{Y}$ chromosomes rather than the cytoplasm is responsible for the majority of the weight difference. Furthermore, the effect reverses the sexual dimorphism in body size, typical for both species, wherein males are smaller than females. We cannot distinguish between an X effect and a $\mathrm{Y}$ effect but as the $\mathrm{Y}$ chromosome is generally genetically depauperate, it is more likely that it is the $\mathrm{X}$ chromosome that is responsible for these differences. Moreover, it is the larger of the $F_{1}$ male hybrids ( $\mathrm{c}$ male $\times \mathrm{F}$ female) that receives its $\mathrm{Y}$ chromosome from $T$. castaneum, the smaller of the two parental species; thus the size differences are probably not due to a Y effect.

The deformities of the distal segments of the male antennae and legs observed in this same cross but not in the reciprocal follow the same pattern as male weight. These reciprocal (apparent large $\mathrm{X}$ ) effects for morphology contrast with the results from Drosophila hybridizations. We suggest that the difference may be due to different genetic architectures being responsible for the traits observed here, body size and antennal integrity, compared with the traits studied in Drosophila hybridizations (e.g. genital arch shape (Coyne, 1985) and colour band size (Spicer, 1991)).

The large differences in the productivities among and within strains in the interspecific crosses is evidence that there is variation for hybrid inviability. Hybrid inviability as a form of postmating reproductive isolation is generally thought not to be adaptive in itself but the by-product of different adaptive or neutral changes evolving within each of two nascent species (Dobzhansky, 1937; Mayr, 1963; Charlesworth et al., 1987; Coyne, 1992b; Wu \& Davis, 1993). Coyne (1974), however, has argued that hybrid inviability itself may be an adaptive trait if the hybrids are sterile and there is parental care. He argues that, if the hybrids are sterile (either physiologically or behaviourally), it would be costlier to provide parental care than to have them be inviable. We believe that competition occurring within families may substitute for the requirement of parental care in Coyne's argument. That is, if individuals produce both sterile hybrids and purespecies progeny and the different types of progeny compete for resources, selection between families would favour the (early) inviability of hybrids.

These conditions may be met in natural populations of Tribolium. First, almost all of the hybrids between $T$. freemani and $T$. castaneum are completely sterile (Brownlee \& Sokoloff, 1988; Wade et al., 1994; this study). Secondly, there is evidence that the densities of Tribolium populations may be regulated at a smallspatial scale giving rise to within-family competition (Park et al., 1964; Sokoloff, 1974; McCauley \& Wade, 1980). Wade \& Beeman (1994) have suggested, on theoretical grounds, that the spread of the Medea selfish element present in Tribolium, is facilitated by within-family competition. Likewise, we suggest that the within-family competition may have facilitated the evolution of hybrid inviability. Here we have shown that significant variation exists among populations of $T$. castaneum as well as among families within populations for this potentially adaptive trait.

\section{Acknowledgements}

We thank Nancy Chang, Michael McNaughton and Ora Lucas for technical assistance. We thank Jerry Coyne, John Kelly, Mohamed Noor, Mike Palopoli and Chung-I Wu for discussion of and/or comments on the manuscript. This work has been supported by a National Institutes of Health grant (GM 22523) to M.J.W.

\section{References}

BOCK, I. R. 1984. Interspecific hybridizations in the genus Drosophila. Evol. Biol., 18, 41-70.

BRownleE, A. AND SOKOloff, A. 1988. Transmission of Tribolium castaneum (Herbst) mutants to $T$. castaneum-T. freemani Hinton hybrids (Coleoptera: Tenebrionidae). J. Stored Prod. Res., 24, 145-150. 
CARSON, H. L. 1975. The genetics of speciation at the diploid level. Am. Nat., 109, 83-92.

ChARLESWORTH, B., COYNE, J. A. AND BARTON, N. H. 1987. The relative rates of evolution of sex chromosomes and autosomes. Am. Nat., 130, 113-146.

COYNE, J. A. 1974. The evolution of hybrid inviability. Evolution, 28, 505-506.

COYNE, J. A. 1985. Genetic studies of three sibling species of Drosophila with relation to theories of speciation. Genet. Res., 46, 169-192.

COYNE, J. A. 1992a. Genetics of sexual isolation in females of the Drosophila simulans species complex. Genet. Res., 60 , 25-31.

COYNE, J. A. 1992b. Genetics and speciation. Nature, 355, 511-515.

COYNE, J. A. 1993. The genetics of an isolating mechanism between two sibling species of Drosophila. Evolution, 47, 778-788.

COYNE, J. A. AND ORR, H. A. 1989a. Two rules of speciation. In: Otte, D. and Endler, J. (eds) Speciation and its Consequences, pp. 180-207. Sinauer Press, Sunderland, MA.

COYNE, J. A. AND ORR, H. A. 1989b. Patterns of speciation in Drosophila. Evolution, 43, 362-381.

COYNE, J. A., ORR, H. A. AND FUTUYMA, D. J. 1988. Do we need a new species concept? Syst. Zool, 37, 190-200.

CROW, J. F. 1942. Cross fertility and isolating mechanisms in the Drosophila mulleri group. University of Texas Publication 4228, pp. 53-67.

Dobzhansky, TH. 1937. Genetics and the Origin of Species. Columbia University Press, New York.

HALDANE, J. B. S. 1922. Sex ratio and unisexual sterility in hybrid animals. J. Genet., 12, 101-109.

HINTON, H. E. 1948. A synopsis of the genus Tribolium MacLeay, with some remarks on the evolution of its species-groups (Coleoptera: Tenebronidae). Bull. Ent. Res., 39, 13-55.

HUTTER, P., ROOTE, J. AND ASHBURNER, M. 1990. A genetic basis for the inviability of hybrids between sibling species of Drosophila. Genetics, 124, 909-920.

JOHNSON, N. A. AND WU, C.-I. 1993. Evolution of postmating reproductive isolation: measuring the fitness effects of chromosomal regions containing hybrid male sterility factors. Am. Nat., 134, 213-223.

McCAULEY, D. E. AND WADE, M. J. 1980. Group selection: the phenotypic and genotypic differentiation of small populations. Evolution, 34, 813-821.

MAYr, E. 1963. Animal Species and Evolution. Harvard University Press, Cambridge, MA.

NAKAKITA, H., IMURA, O. AND WINKS, R. G. 1981. Hybridization between Tribolium freemani (Hinton) and Tribolium castaneum (Herbst) and some preliminary studies on the biology of Tribolium freemani (Coleoptera, Tenebrionidae). Appl. Ent. Zool., 16, 209-215.

NEI, M., MARUYAMA, T. AND WU, C.-I. 1983. Models of evolution of reproductive isolation. Genetics, 103, 557-579.

ORR, H. A. 1993. Haldane's rule has multiple genetic causes. Nature, 361, 532-533.

PARK, T. 1933. Studies in population physiology. II. Factors regulating initial growth of Tribolium confusum populations. Exp. Zool., 65, 17-42.

PARK, T., LESLIE, P. H. AND MERTZ, D. B. 1964. Genetic strains and competition in populations of Tribolium. Phys. Zool., 37, 97-161.

PARTRIDGE, L. 1993. Haldane's rule and the hazards of heterogametity. Curr. Biol., 3, 56-58.

SAWAMURA, K., TAIRA, T. AND WATANABE, T. K. 1993. Hybrid lethal systems in the Drosophila melanogaster species complex. I. The maternal hybrid rescue $(\mathrm{mhr})$ gene of Drosophila simulans. Genetics, 133, 299-305.

SAWAMURA, K., YAMAMOTO, M. T. AND WATANABE, T. K. 1993b. Hybrid lethal systems in the Drosophila melanogaster species complex. II. The Zygotic lethal rescue gene of Drosophila melanogaster. Genetics, 133, 307-313.

sokoloff, A. 1974. The Biology of Tribolium, vol. 2. Clarendon Press, Oxford.

SPICER, G. C. 1991. The genetic basis of a species-specific character in the Drosophila virilis species group. Genetics, 128, 331-337.

TEMPLETON, A. R. 1977. Analysis of head shape differences between two interfertile species of Hawaiian Drosophila. Evolution, 31, 630-641.

TEMPLETON, A. R. 1980. The theory of speciation via the founder principle. Genetics, 94, 1011-1038.

WADE, M. J. 1977. An experimental study of group selection. Evolution, 31, 134-153.

WADE, M. J. AND BEEMAN, R. 1994. The population dynamics of maternal-effect selfish genes. Genetics (in press).

WADE, M. J. PATTERSON, H., CHANG, N. AND JOHnSON, N. A. 1994. Postcopulatory, prezygotic isolation in flour beetles. Heredity, 72, 163-167.

WATANABE, T. K. 1979. A gene that rescues the lethal hybrids between Drosophila melanogaster and D. simulans. Jpn J. Genet., 52, 1-8.

wU, C. I. 1992. A note on Haldane's rule: Hybrid stability versus hybrid inviability. Evolution, 46, 1584-1587.

WU, C.-I. AND DAVIS, A. W. 1993. The composite nature of Haldane's rule and its genetic bases. Am. Nat., 134, 189-212. 